\title{
O PAPEL DA VANTAGEM COMPETITIVA NA RELAÇÃO ENTRE INTERNACIONALIZAÇÃO E DESEMPENHO DAS EXPORTAÇÕES: ESTUDO DE CASO DA EFACEC
}

\section{RESUMO}

O objetivo fundamental deste estudo consiste em analisar os fatores que no processo de internacionalização das empresas portuguesas permitem compreender as contribuições da vantagem competitiva que influem no desempenho das exportações do sector electromecânico. Tal permitirá avaliar de que forma as estratégias de internacionalização, considerando a vantagem competitiva, bem como a respetiva interacção com as caraterísticas do mercado, poderão conduzir as empresas, por um lado, à implementação de estratégias de sucesso e, por outro, a desempenhos superiores ao nível da sua atividade exportadora. Neste contexto, utilizamos uma abordagem metodologia qualitativa, recorrendo para o efeito ao estudo de caso único da maior e mais representativa empresa multinacional portuguesa do setor electromecânico (EFACEC), permitindo assim uma visão holística e integrada dos fenómenos organizacionais objeto de estudo. Esta opção metodológica permitiu objetivar resultados de importância prática, os quais contribuirão para uma menor dispersão estratégica das empresas no processo de internacionalização, acentuando a assertividade da sua atividade exportadora. Como principais conclusões destacamos o fato das estratégias de internacionalização potenciarem positivamente a obtenção de vantagem competitiva que, por sua vez, influenciam positivamente o desempenho das exportações, sendo estas últimas positivamente influenciadas pelas caraterísticas do mercado.

Palavras-chave: Estratégia; Vantagem Competitiva; Internacionalização; Exportações.

THE ROLE OF COMPETITIVE ADVANTAGE ON THE RELATION BETWEEN INTERNATIONALIZATION AND EXPORT PERFORMANCE: CASE STUDY OF EFACEC

\begin{abstract}
The main goal of this study is to analyze the factors that in the internationalization's process of Portuguese companies that allows to understand the contributions of the competitive advantage that influenced export performance. This will assess how the internationalization's strategies, considering the competitive advantage as well its interaction with the market's characteristics, may lead companies, on the one hand, to the implementation of strategies for success, and, on the other, and to the top performances of its export activity. In this context embarked by the qualitative methodology, we used the case study method, regarding to the single case of the largest and the most representative Portuguese multinational company of the electromechanical sector (EFACEC), thus enabling a holistic and integrated vision of organizational phenomena object of study. This methodological option allowed objectify results of practical importance, which will contribute to a lower dispersion in companies' strategic internationalization process, accentuating the assertiveness of its exporting activity. As main conclusions we highlight the fact of internationalization's strategies positively influence competitive advantage which, in turn, positively influence the export performance, and this one is positively influenced by markets' characteristics.
\end{abstract}

Keywords: Strategy; Competitive Advantage; Internationalization; Export. 
O Papel da Vantagem Competitiva na Relação entre Internacionalização e Desempenho das Exportações: Estudo de Caso da EFACEC

\section{EL PAPEL DE LA VENTAJA COMPETITIVA EN RELACIÓN ENTRE LA INTERNACIONALIZACIÓN Y DESEMPEÑO DE LAS EXPORTACIONES: UN ESTUDIO DE CASO DE EFACEC}

\section{RESUMEN}

El objetivo fundamental de este estudio es analizar los factores en el proceso de internacionalización de las empresas portuguesas nos permiten comprender las contribuciones de la ventaja competitiva que influyen en el comportamiento de las exportaciones del sector electromecánico. Este evaluará cómo las estrategias de internacionalización, teniendo en cuenta la ventaja competitiva y la respectiva interacción con las características del mercado, podría llevar a las empresas, por un lado, la implementación de estrategias de éxito y, por otro, el rendimiento superior el nivel de su actividad exportadora. En este contexto, se utiliza un enfoque de la metodología cualitativa, utilizando para ello el estudio de caso único de la multinacional portuguesa más grande y representativa del sector electromecánico (Efacec), lo que permite una visión holística e integrada del objeto fenómenos de organización del estudio. Esta elección metodológica permitió objetivar resultados de importancia práctica, lo que contribuirá a una menor dispersión de empresas estratégicas en el proceso de internacionalización, lo que acentúa la agresividad de su actividad exportadora. Las principales conclusiones destacan el hecho de que las estrategias de internacionalización potencian positivamente ganar ventaja competitiva que, a su vez, influye positivamente en el comportamiento de las exportaciones, siendo este último influenciado positivamente por las características del mercado.

Palabras-clave: Estrategia; Ventaja Competitiva; Internacionalización; Exportaciones.

\footnotetext{
${ }^{1}$ Ph.D in Economics and Management Researcher da Unidade de Investigação Aplicada à Gestão da Associação de Politécnicos do Norte UNIAG/APNOR, Portugal. Pesquisador do Centro de Estudos em Ciências Empresasriais CECEJ, Instituto Politécnico do Porto - IPP e Instituto Superior de Contabilidade e Administração - ISCAP. Portugal. E-mail: orlandorua@gmail.com

${ }^{2}$ Mestre pela Associação de Politécnicos do Norte - APNOR. Portula. E-mail: melo_liliana@ hotmail.com
} 


\section{INTRODUÇÃO}

O fenómeno da globalização é uma realidade incontornável do qual resultou uma maior integração entre indivíduos, empresas e países, afetando os fluxos de mercadorias, capital, serviços e pessoas devido à diminuição de barreiras restritivas de livre comércio e viagens (Peng, 2006), tendendo o mundo a tornar-se cada vez mais homogéneo, por via de uma nova realidade comercial em mercados globais com produtos padronizados e consumidores em larga escala. Neste contexto, a competição global dita o fim da territorialidade doméstica, não importando quão diminuto seja o território.

Barney (2001) defende que com a existência de novos padrões competitivos terá necessariamente de haver estratégias diversas na entrada e expansão das empresas nos mercados internacionais, passando muitas destas a encarar a internacionalização como uma meta facilmente alcançável, devido aos custos marginais associados, quando comparada com as outras formas tradicionais de internacionalização. A crescente liberalização do mercado e da concorrência na economia mundial, aliada às dificuldades de desempenho sentidas pelos exportadores podem assim explicar o crescimento da pesquisa nesta área (Leonidou, Katsikeas e Samiee, 2002).

A questão de partida deste estudo consubstancia-se assim em analisar qual o papel que a vantagem competitiva pode desempenhar no processo de internacionalização das empresas portuguesas do sector eletromecânico, com vista a alcançar desempenhos competitivos superiores, designadamente ao nível das suas exportações, identificando para tal as variáveis mais relevantes para o efeito. Morgan, Kaleka e Katsikeas (2004) revelam que o desempenho das exportações está fortemente relacionado com a vantagem posicional da empresa no mercado internacional e que esta está diretamente relacionada com a disponibilidade de recursos e capacidades para os mercados externos. Habitualmente a vantagem competitiva é estudada tendo por base a ResourceBased View (RBV), sugerindo esta que a fonte básica para obtenção de uma vantagem competitiva está alicerçada nos recursos e capacidades desenvolvidos e controlados pela empresa, os quais são elementos raros, valiosos, insubstituíveis e de difícil imitação (Barney, 1991). Esta teoria defende que a inimitabilidade da combinação dos recursos utilizada para conceber e implementar estratégias competitivas é importante no desempenho da empresa. As premissas do presente estudo, incorporando a RBV, procuram novos caminhos para analisar a contribuição da vantagem competitiva no sentido da sustentabilidade do processo de internacionalização, com vista a consolidar a formulação de estratégias que permitam a obtenção de um melhor desempenho das exportações.

\section{FUNDAMENTAÇÃO TEÓRICA}

Hitt, Ireland e Hoskisson (2007) identificam "estratégia internacional" como o estratagema pelo qual a organização vende ou presta serviços fora do seu mercado local. Em detrimento dos relacionamentos resultantes dos contatos com os novos clientes, fornecedores ou sócios, nesses mercados além fronteiras, as empresas sofrem um processo de aprendizagem. Quando bem sucedidas obtêm vários tipos de benefícios, como retornos superiores para os seus investimentos (quer de capital, quer de novos produtos ou processos), ampliação do seu mercado, vantagem competitiva (através do acesso a recursos críticos, clientes, mão-de-obra barata, economias de escala, aprendizagem e escopo). Para Maçães e Dias (2001) o ato que conduz à internacionalização é uma decisão estratégica, que envolve a identificação dos produtos a colocar nos mercados internacionais, os mercados a atingir e os modos de acesso e de presença mais adequados.

O modelo de internacionalização de Uppsala considera a internacionalização de uma empresa um processo incremental na construção de compromisso num mercado externo (Johanson e Vahlne, 1977), consubstanciando-se no modelo mais utilizado no estudo do processo de internacionalização. Trata-se de um processo gradual que parte do pressuposto que a decisão de internacionalização se devia à incerteza dos lucros no país de origem e devido à imperfeição de informações (Resende, 2002). Inicialmente, as empresas procuravam mercados em países menos distantes física, cultural e psiquicamente e gradualmente, à medida que as empresas adquiriam maior experiência e mais recursos, expandiam-se para mercados mais distantes (Pedersen, 1999; Zohari, 2008).

Nessa perspetiva, a experiência adquirida ou as trocas de experiência eram cruciais para o processo, sendo que à medida que a experiência e o conhecimento aumentavam as empresas tendiam gradualmente a eleger países mais "distantes psiquicamente" (Pedersen, 1999; Resende, 2002; Johanson e Vahlne, 2007; Zohari, 2008). Chave do processo de internacionalização, o conhecimento tanto poderia advir da sua própria experiência como do intercâmbio de informações. Do seu estudo sobre conhecimento, experiência, capacidades de marketing e desempenho das exportações Morgan, Shaoming, Vorhies e Katsikeas (2003) resultou uma relação positiva entre estes fatores e os resultados da 
exportação. O conhecimento e a experiência base seriam valiosos uma vez que possibilitariam às empresas exportadoras utilizar o planeamento do marketing e o desenvolvimento de capacidades que lhes permitissem adaptar-se às exigências desse mercado.

Alguns autores (e.g. Madhok, 1997; Vila e Kuster, 2007) sustentam que o modo de entrada ou a forma como uma empresa está presente no mercado internacional indica o seu grau de envolvimento em mercados externos, correspondendo, habitualmente, a primeira fase do processo de internacionalização à exportação. Esta forma de internacionalização implica um menor envolvimento e um baixo risco associado, utilizando serviços de agentes e intermediários estabelecidos no mercado externo para comercializar o produto nesse mercado (Vila e Kuster, 2007).

Håkansson e Johanson (1984, citados por Lorga, 2002) definem o conceito de rede como a interligação de relacionamentos entre organizações. Nesta rede os atores representariam quem controla os recursos (indivíduos, grupos ou empresas, ou partes destas), podendo pertencer a distintos níveis da organização, estabelecendo estes relacionamentos através de troca onde os laços que os unem poderiam ser de natureza diversa: económicos, estratégicos, técnicos, socioculturais, legais ou de know-how. Compreendendo atividades como transferência ou de transformação, ocorrendo através da utilização de recursos ou mudança destes (Lorga, 2002). Johanson e Mattson (1988, citados por Dias, 2007) defendiam que a posição da empresa dentro da rede seria determinante para a obtenção de vantagem competitiva, pois dela dependeriam as suas oportunidades, constrangimentos e até as suas estratégias, sendo os seus recursos e a sua capacidade de obtenção dos mesmos, ou de coordenação e de mobilização dos recursos de terceiros a seu favor, elementos chave da vantagem competitiva.

Esta perspetiva converge com a teoria das redes internacionais, a rede carateriza-se pois por relacionamentos baseados na confiança e no comprometimento, sendo, portanto, cooperar numa rede seria um pré-requisito para o sucesso. Nesta senda, Dalmoro e Wittmann (2011, pp. 231-242) reforçam a ideia de que a associação em redes "forma um ambiente propício para a internacionalização" atuando como um suporte para ultrapassar as barreiras do processo. Por sua vez, Moreno (2005) reforça a necessidade da cooperação como suporte de uma atitude ativa face à inovação. Essa postura representa, na sua generalidade, casos de sucesso de internacionalização, salientando a importância das trocas de informações, bem como das relações pessoais nos processos de internacionalização.

Pelo que os vínculos relacionais têm sido qualificados como recursos que têm o potencial de contribuir para a capacidade de uma empresa criar valor (Davis e Mentzer, 2008) e encarados como decisivos no desempenho das exportações (Ambler, Styles e Xiucun, 1999; Morgan et al., 2006).

Daqui decorrem as seguintes proposições de trabalho (tabela 1):

\section{P1: A internacionalização potencia positivamente a obtenção de vantagem competitiva.}

P2: Poderá a internacionalização influenciar e ser influenciada positivamente pelas caraterísticas do mercado.

Para Barney (1991) a vantagem competitiva consiste na implementação estratégica que possibilita a determinada empresa criar valor e não seja, ou não possa ser, simultaneamente, implementada pelos seus concorrentes (atuais ou potenciais). Prossegue referindo que a vantagem competitiva não pode existir para empresas idênticas, dado, se assim for, estas implementam as mesmas estratégias, que irão conduzir à referida criação de valor por via da eficiência e eficácia de forma semelhante, anulando assim o efeito desejado da vantagem competitiva.

Já Porter (1989, 1999) sustenta que vantagem competitiva seria o resultado da capacidade da empresa de realizar eficientemente o conjunto de atividades necessárias para obter um custo mais baixo que o dos seus competidores ou de organiza-las de uma forma única, capaz de gerar um valor diferenciado para os compradores, referindo ainda que a escolha de uma posição exclusiva não seria suficiente para garantir uma vantagem sustentável. A ênfase na estrutura da indústria e no posicionamento competitivo são representativos dessa linha de pensamento onde os principais desenvolvimentos da análise estratégica focavam a ligação entre o ambiente externo e a estratégia das forças do mercado (Grant, 1991).

A RBV tornou-se numa das teorias mais utilizadas em gestão estratégica (Beard e Sumner, 2004; Runyan, Huddleston e Swinney, 2006), descrevendo esta os recursos que a empresa integra. Vários autores (e.g. Wernerfelt, 1984; Barney, 1991; Peteraf, 1993), partindo das premissas desta teoria, argumentam que os recursos (e as capacidades) estratégicos permitem às empresas obter substanciais vantagens competitivas, indicando estas que uma empresa pode obter melhor desempenho de que o dos concorrentes na mesma indústria utilizando os seus recursos e capacidades (Lee e Hsien, 2010), sendo estes explicados por factores internos da empresa que possam consubstanciar forças ou fraquezas (Wernerfelt, 1984). Miller e Shamsie (1996) referem que os recursos deverão ter a capacidade de gerar lucros e, consequentemente, evitar prejuízos. Para a empresa alcançar elevado desempenho e vantagem competitiva necessita de adquirir/dispor recursos heterogéneos, difíceis de criar, substituir ou imitar por 
parte dos concorrentes (Ferreira, Azevedo e Fernandéz, 2011).

Bakar e Ahmad (2010) referem que a vantagem competitiva sustentável é a base de superior desempenho, sobrevivência e desenvolvimento organizacional. Neste sentido, o posicionamento da empresa dentro da indústria era o principal determinante do seu sucesso ou fracasso na competição, em que o objetivo estratégico era encontrar a posição dentro da indústria, onde a empresa pudesse melhor defender-se contra as forças competitivas ou influenciá-las a seu favor (Porter, 1999). Este contexto progrediria, de acordo com a pressão das forças do mercado e da ação dos competidores levando à alteração dos posicionamentos (Anastassopoulos, Détrie, Santi, et al., 2000). Nesse sentido Shoham (1998) define desempenho das exportações como o resultado composto pelas vendas internacionais da empresa, que inclui as vendas, lucro e crescimento das exportações, apresentando Zou e Stan (1998) uma definição mais ampla e completa que conceitualiza desempenho das exportações como o desempenho financeiro e estratégico das exportações e a satisfação da empresa com o desempenho das exportações. Para Zou, Taylor e Osland (1998) os aspetos centrais para aferir do desempenho das exportações são financeiros (e.g. lucro e vendas de exportação), estratégicos (e.g. quotas de mercado) e satisfação do desempenho de exportação, pelo que somente por via da obtenção de vantagens competitivas tal serão objetivos alcançáveis, caso contrário o posicionamento da empresa na estrutura da indústria degradar-se-á. O desempenho das exportações é entendido como a extensão em que os objetivos da empresa relativamente à exportação são alcançados através do planeamento e execução da estratégia de marketing para a exportação (Cavusgil e Zou, 1994).

Assim, propomos as seguintes proposições de trabalho (tabela 1):

P3: As caraterísticas do mercado influenciam positivamente a obtenção de vantagem competitiva.

P4: A obtenção de vantagem competitiva influencia positivamente o desempenho das exportações.

P5: As caraterísticas do mercado influenciam positivamente o desempenho das exportações.

Tabela 1 - Fundamentação teórica das proposições de investigação (agrupamento concetual)

\begin{tabular}{|c|c|c|c|}
\hline CONSTRUTO & DIMENSÃO & PROPOSIÇÃO & PRINCIPAIS AUTORES \\
\hline Internacionalização & $\begin{array}{l}\text { Vantagem } \\
\text { competitiva }\end{array}$ & $\begin{array}{l}\text { P1: A internacionalização } \\
\text { potencia positivamente a } \\
\text { obtenção de vantagem } \\
\text { competitiva? }\end{array}$ & $\begin{array}{l}\text { Barney (1991; 1986), Porter (1992, 1998, } \\
\text { 1999), Simões (1997), Dias (2007), Grant } \\
\text { (2002), Forte, Moreira e Moura (s/d), Lima } \\
\text { e Forte (s/d). }\end{array}$ \\
\hline Internacionalização & $\begin{array}{l}\text { Caraterísticas } \\
\text { do mercado }\end{array}$ & $\begin{array}{l}\text { P2: Poderá a } \\
\text { internacionalização } \\
\text { influenciar e ser influenciada } \\
\text { positivamente pelas } \\
\text { caraterísticas do mercado? }\end{array}$ & $\begin{array}{l}\text { Alexsson e Johanson (1992), } \\
\text { (1995), Ramos (1995), Cateora } \\
\text { Schneider (2002), Teixeira } \\
\text { (2003), } \\
\text { Teixeira e Diz (2005), Freire } \\
\text { Export Manager (2008). }\end{array}$ \\
\hline $\begin{array}{l}\text { Caraterísticas do } \\
\text { mercado }\end{array}$ & $\begin{array}{l}\text { Vantagem } \\
\text { competitiva }\end{array}$ & $\begin{array}{l}\text { P3: As caraterísticas do } \\
\text { mercado influenciam } \\
\text { positivamente a obtenção de } \\
\text { vantagem competitiva? }\end{array}$ & $\begin{array}{l}\text { Porter (1999), Barney (2001), Teixeira e } \\
\text { Diz (2005), Hitt et al. (2007), Freire } \\
\text { (2008). }\end{array}$ \\
\hline $\begin{array}{l}\text { Vantagem } \\
\text { competitiva }\end{array}$ & $\begin{array}{c}\text { Desempenho } \\
\text { das exportações }\end{array}$ & $\begin{array}{l}\text { P4: A obtenção de vantagem } \\
\text { competitiva influencia } \\
\text { positivamente o desempenho } \\
\text { das exportações? }\end{array}$ & $\begin{array}{l}\text { Sacramento et al. (s/d), Axxin (1988), } \\
\text { Cavusgil e Zou (1994), Zou e Stan (1998), } \\
\text { Zou et al. (1998), Grant (2001), Forcadell } \\
\text { (2001), Sacramento et al. (2002), Arbix et } \\
\text { al. (2004), Ruigrok e Wagner (2003), } \\
\text { Morgan et al. (2004). }\end{array}$ \\
\hline $\begin{array}{l}\text { Caraterísticas do } \\
\text { mercado }\end{array}$ & $\begin{array}{c}\text { Desempenho } \\
\text { das exportações }\end{array}$ & $\begin{array}{l}\text { P5: As caraterísticas do } \\
\text { mercador influenciam } \\
\text { positivamente o desempenho } \\
\text { das exportações? }\end{array}$ & $\begin{array}{l}\text { Cavusgil e Zou (1994), Kotler (1996), Zou } \\
\text { et al. (1998), Bueno e Aguiar (2004), } \\
\text { Freire (2008). }\end{array}$ \\
\hline
\end{tabular}

Face à revisão da literatura efetuada, elaboramos o modelo concetual de investigação visando a representação organizada e abstrata de conceitos que se pretendem testar (Sousa e Baptista,
2011), por via de uma abordagem metodologia qualitativa, utilizando especificamente o estudo de caso único (figura 1). 
O Papel da Vantagem Competitiva na Relação entre Internacionalização e Desempenho das Exportações: Estudo de Caso da EFACEC

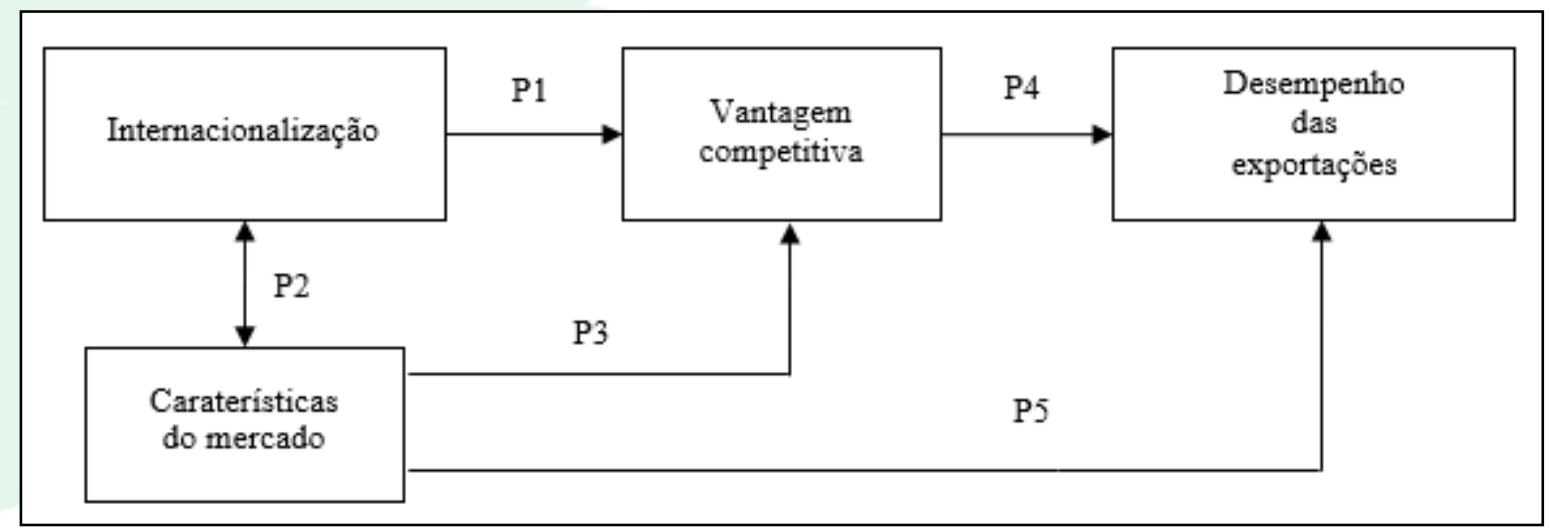

Figura 1- Modelo concetual de investigação

\section{METODOLOGIA}

A utilização do caso como instrumento para a investigação científica, identificando as diversas fases existentes no desenho e na realização deste tipo de estudos foi objeto de estudo de Yin (1994) que resultou num valioso contributo disponível na literatura. Relativamente ao método, optamos pelo estudo de caso único devido à coesão metodológica que fornece e à possibilidade de incorporar no estudo dados de natureza predominantemente qualitativa.

Rodríguez, Gil e García (1996) integram o modelo de Yin, resultando daí um modelo mais detalhado e preciso, onde existem quatro fases fundamentais em qualquer investigação de carácter qualitativo: a preparatória; o trabalho de campo; a analítica; e a informativa. Cada uma destas fases descomponhem-se, por sua vez, em outras. Desta forma na fase preparatória podemos encontrar uma etapa de reflexão e outra em que se realiza o desenho da investigação. Na fase de trabalho de campo existem também duas etapas, a de acesso ao campo e a da recolha de informação. $\mathrm{Na}$ fase analítica distinguem-se três etapas: i) a da redução de dados; ii) a disposição e transformação de dados; e iii) a obtenção de resultados e verificação de conclusões. A fase informativa limitase à elaboração do relatório (no nosso caso este consubstancia-se no presente artigo). Cada uma das fases gera um produto distinto, a preparatória o projecto de investigação, o trabalho de campo os dados acumulados, a analítica os resultados da investigação e, por último, a informativa o relatório de investigação (figura 2). 


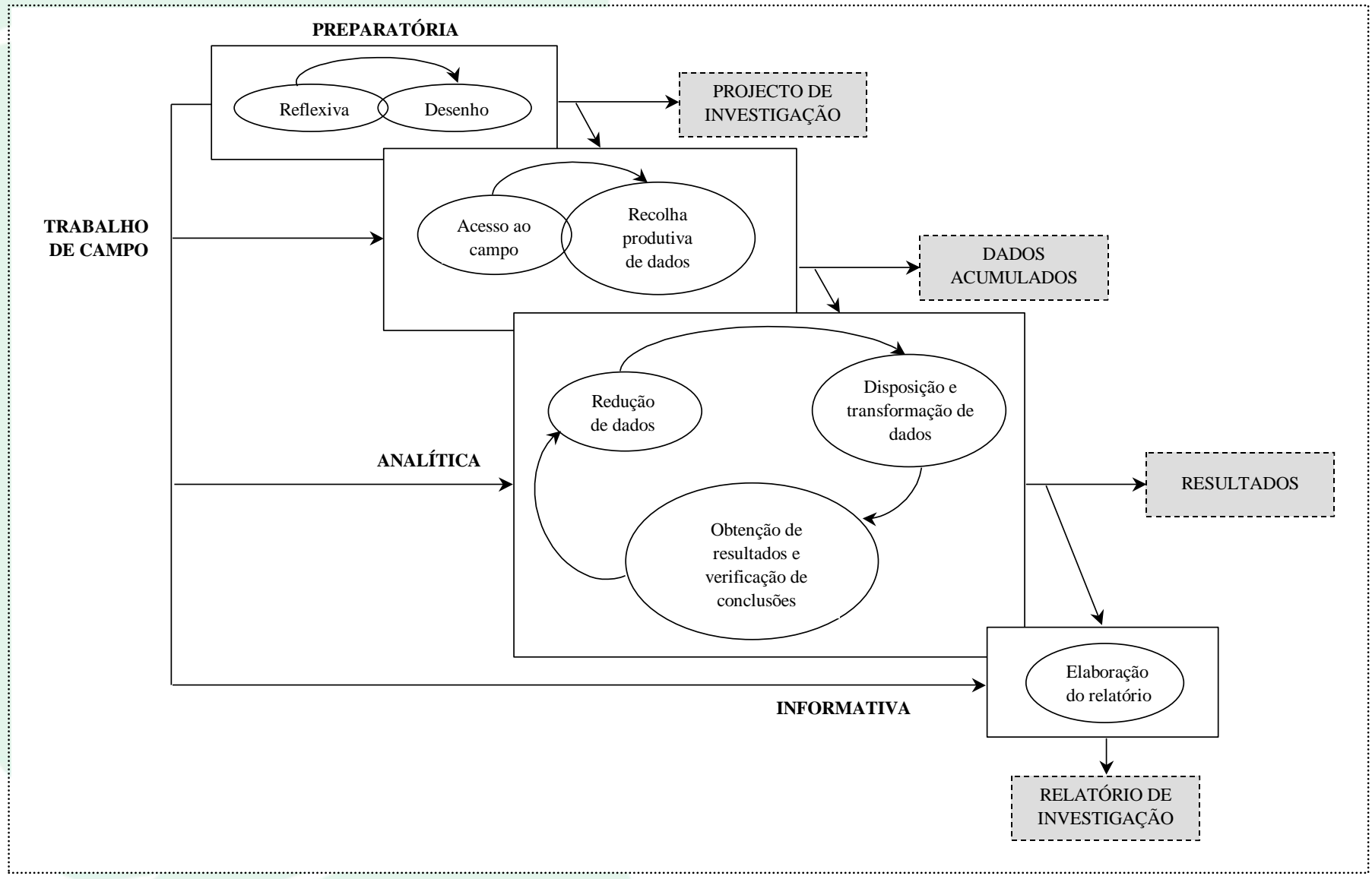

Figura 2 - Fases e etapas da investigação

Fonte: Rodriguez, Gil e García (1996, p. 64).

A triangulação metodológica obtém-se através da utilização de distintos métodos. No entanto, numa investigação qualitativa, deve contemplar-se a triangulação de dados, do investigador, teórica e disciplinar (Denzin, 1978; Janesick, 1994). Neste estudo tivemos em consideração as distintas formas de triangulação mencionadas na literatura procurando assim reforçar a validade e confiabilidade do mesmo.

No que respeita ao papel e à importância das entrevistas, Stokes (2000, p. 53) notou que "as entrevistas em profundidade já provaram a sua utilidade na investigação". A compreensão profunda de um fenómeno implica a realização de entrevistas em profundidade e a análise de um número limitado de fontes, que permitam obter uma quantidade adequada de dados (Patton, 1990). Porquanto, realizamos entrevistas individuais, com utilização de guião de entrevista semi-estruturado com questões criadas a partir das escalas propostas pelos autores apresentados na tabela 1, para todos os indivíduos do estudo de caso, procurando colher descrições da realidade dos entrevistados para a interpretação do significado e práticas dos fenómenos estudados, tendo como caraterísticas essenciais: (a) médio grau de estruturação, (b) perguntas abertas e (c) foco em situações específicas e sequenciais da ação do entrevistado. Neste tipo de entrevistas, em profundidade, as perguntas de resposta aberta típicas, permitiram uma maior profundidade de informações do que as entrevistas estruturadas, na medida em que tentaram "compreender o comportamento complexo dos membros da sociedade sem impor nenhuma categorização apriorística que possa limitar o campo da investigação" (Fontana e Frey, 1994, p. 362). Estas perguntas são particularmente adequadas quando importa compreender o construto que os entrevistados utilizam como base para os seus pontos de vista ou crenças sobre uma temática específica (Easterby-Smith, Thorpe e Lowe, 1991).

Tendo em consideração a estrutura organizacional matricial do Grupo EFACEC e com vista a obter uma visão holística, os entrevistados selecionados são executivos que ocupavam cargos de gestão de topo e/ou de liderança da atividade de exportação sendo o primeiro da área de estratégica, o segundo de uma unidade estratégica de negócio e o terceiro responsável pelo marketing internacional. Considera-se estas pessoas como as mais indicadas 
para serem entrevistadas, devido ao seu envolvimento e responsabilidade direta nas decisões de exportação (Miesenböck, 1988), verificando-se que a maioria dos estudos realizados neste âmbito foram obtidos a partir da pessoa responsável pela atividade de exportação (Sousa, Martínez-López e Coelho, 2008). Salientamos a relevante experiência dos entrevistados no que concerne às temáticas em estudo. $\mathrm{O}$ entrevistado da área estratégica trabalha no grupo há 24 anos, ocupando a atual posição há 8 anos. O responsável pela unidade de negócio ocupou anteriormente uma posição de administração executiva de uma área estratégica e antes disso foi responsável pelos recursos humanos. Por último, o atual responsável pelo marketing internacional já ocupou funções noutra área estratégica. Pensamos serem estes os colaboradores mais habilitados ao nível do conhecimento (académico e profissional) para, de uma forma crítica e proativa, se pronunciarem sobre as temáticas desta investigação. As entrevistas ocorreram entre Outubro e Novembro de 2011.

\subsection{Estudo do caso: Grupo EFACEC}

No âmbito da presente investigação optamos por estudar o Grupo EFACEC pelo fato de ser o maior grupo electromecânico português, tendo realizado um estudo de caso único tal como recomendado por Rua (2012). Consideramos este grupo como exemplificativo das empresas electromecânicas portuguesas que competem em contexto internacional com os maiores players dos mercados de referência.

Fundado em 1948, com o nome de "Electro Moderna", a EFACEC fabricava inicialmente motores, geradores eléctricos. Atualmente, opera em 5 continentes, estando presente em 65 países, directa ou indirectamente, tendo $66 \%$ da sua facturação no mercado externo em 2010. Emprega cerca de 4600 funcionários a nível mundial, dos quais $65 \%$ tem formação superior e dentre estes, 150 estão dedicados em exclusividade a atividades de I\&D. Em 2006, a empresa foi comprada pelo Grupo José de Mello e pela Têxtil Manuel Gonçalves, deixando de estar em bolsa (EFACEC, 2009). A partir daí, deu-se uma importante viragem no processo de internacionalização com a criação de um plano estratégico 2008-2012 visando reposicionar-se e potenciar a sua posição nos mercados internacionais. Procurando constituir-se como uma multinacional de origem portuguesa, o Grupo EFACEC desenvolveu um novo modelo organizacional que lhe permitiria responder mais eficientemente aos desafios da internacionalização (Mesquita e Ribeiro, 2008, p. 147).

Este grupo apresenta uma estrutura organizacional matricial constituida por dez unidades de negócio, na horizontal, dentro de três áreas estratégicas: (a) energia, (b) engenharia, ambiente e serviços e (c) transportes e logística, e, na vertical, por sete mercados considerados estratégicos além do nacional (Espanha, Europa Central, EUA, América Latina, Magreb, África austral e Índia) (EFACEC, 2010, 2011).

Não tendo um concorrente nacional a atuar no conjunto de todas as áreas em que a empresa trabalha, o estudo de caso da EFACEC é um exemplo representativo do seu setor, pela sua amplitude e dimensão. Por reunir este conjunto de particularidades, considerou-se que o estudo do caso único de uma organização com tais características pudesse representar evidência suficiente para uma investigação desta natureza.

Partimos do princípio de que as lições que se aprendem do estudo de caso único fornecem muitas informações sobre as experiências, neste caso, da organização analisada (Yin, 2005, p. 63). O estudo de caso único revelou-se adequado para se alcançarem os objetivos desta investigação e obter um retrato credível e alargado do fenómeno analisado.

Apesar das palavras serem consideradas a unidade mais exata e fiável para a codificação de dados (Krippendorff, 1980, p. 88; Deegan e Gordon, 1996; Zéghal e Ahmed, 1990), não capturam o significado da mensagem quando consideradas de forma individual (Hackston e Milne, 1996). Relativamente às frases temse dito que são as que melhor recolhem as ideias ou o significado do que se quer transmitir, mas, obviamente, não capturam a informação transmitida por meio de fotografias, gráficos ou tipos de letra (Unerman, 2000). Não obstante o referido, não hesitamos em utilizar no presente estudo como unidade para a codificação de dados a frase.

\section{RESULTADOS}

Da evidência empírica ${ }^{3}$ recolhida nas entrevistas passamos a responder às questões de investigação formuladas (Rua e Melo, 2013).

\section{P1: A internacionalização potencia positivamente a obtenção de vantagem competitiva?}

Nesta questão, existe unanimidade entre os respondentes e uma convergência com os estudos encontrados na literatura, a eleição da estratégia de internacionalização adequada ao mercado e ao produto/serviço em causa, potenciam positivamente a obtenção de vantagem competitiva. Pelo que esta questão é suportada.

Porter (1998) refere que para obter vantagem competitiva é necessário analisar a concorrência e encontrar um segmento do mercado que não esteja completamente bem servido, diversificar o produto ou

\footnotetext{
${ }^{3}$ Não é apresentada por questões de ética e confidencialidade.
} 
a sua imagem, ou ainda, o seu processo produtivo. Segundo este autor, a estrutura da indústria determina o comportamento dos agentes económicos e o desempenho das empresas.

O modo de entrada no mercado internacional está diretamente relacionado à vantagem competitiva a ser obtida pela empresa no país estrangeiro que por sua vez, está relacionado com as motivações das empresas para se internacionalizarem: (a) necessidade de acesso a recursos exteriores, (b) endógenas (aproveitamento de capacidades, necessidade de crescimento, diversificação de riscos, economias de escala, exploração de tecnologias ou de capacidades), (c) incentivos estatais e (d) relacionais (resposta a clientes ou concorrentes), aceso a recursos (conhecimentos tecnológicos ou baixos custos de produção) (Dias, 2007; Simões, 1997).

P2: Poderá a internacionalização influenciar e ser influenciada positivamente pelas caraterísticas do mercado?

Nesta questão, apesar de não existir concordância entre os respondentes e, por sua vez, destes com a literatura, não se suporta esta questão, embora segundo as evidências do estudo empírico, pareça haver uma tendência nesse sentido.

Antes de qualquer tomada de decisão relativamente às estratégias de internacionalização, Teixeira e Diz (2005), numa perspectiva de rede, apontam diversas questões que necessitam ser respondidas, como: Quem são os players (possíveis clientes, fornecedores, concorrentes, agencias oficiais, possíveis parceiros) do mercado? Qual a posição ocupada na rede pelos diversos players na rede? Quais são as relações entre os players? Como mobilizar recursos de outros atores para apoio da entrada no mercado? Assim como existem alguns aspectos essenciais a ter em conta nas decisões relativas à internacionalização, segundo estes autores: (a) selecção do mercado e do produto, (b) objectivos e metas, (c) escolha da forma de entrada, (d) elaboração de um plano de marketing e (e) sistema de controlo e monitorização do desempenho do mercado alvo.

Uma mesma estratégia de sucesso num determinado mercado, necessariamente, poderá não ser utilizada em outros. Portanto, as empresas devem sempre estar buscando informações sobre o ambiente externo, tendo em vista um melhor desempenho face às suas oportunidades e ameaças inerentes aos mercados em causa. Bradley (1995), ao analisar a entrada no mercado internacional, refere que a empresa deve observar a sua disposição dentro deste mercado, ou seja, como irá responder ao ambiente internacional e às suas particularidades. Factores como, idioma, religião, nível educacional, clima, cultura, economia, infraestruturas, recursos económicos e ambientais, distribuição demográfica e legislação, entre outros, devem ser tidos em conta nas de definições estratégicas (Schneider, 2002). Cada nação tem aspetos únicos que devem ser entendidos.

\section{P3: As caraterísticas do mercado influenciam positivamente a obtenção de vantagem competitiva?}

Perante as evidências reunidas, esta questão é suportada parcialmente, dado considerar-se existir alguma convergência entre as posições dos entrevistados e a literatura.

Sendo que a maioria das empresas que encetaram processo(s) de internacionalização iniciavam-no(s) através de exportação ou licenciamento, devido aos baixos custos e riscos reduzidos (Hitt et al., 2007).

$\mathrm{Na}$ perspetiva das forças dos mercados, Porter (1999) defende que o posicionamento da empresa dentro da indústria é o principal determinante do seu sucesso ou fracasso na competição. Sendo o seu objetivo estratégico o de encontrar a posição dentro da indústria onde a empresa possa melhor defender-se contra as forças competitivas ou influenciá-las a seu favor. A construção de barreiras à entrada de outros competidores na indústria seria a melhor forma de impedir a diminuição das margens de lucro. Por essa razão, os monopólios e os oligopólios eram as indústrias mais atrativas.

Do ponto de vista dos recursos, Barney, Wright e Ketchen (2001) fundamentam que o argumento de que as empresas podem obter vantagem competitiva sustentável através da implementação de estratégias que fomentem as suas forças, em resposta às oportunidades ambientais, neutralizando as ameaças externas e evitando as suas fraquezas.

\section{P4: A obtenção de vantagem competitiva influencia positivamente o desempenho das exportações?}

Relativamente a esta quarta questão, existe unanimidade, quer entre os respondentes, quer em relação à revisão da literatura, no que respeita ao facto da obtenção de vantagem competitiva influenciar positivamente o desempenho das exportações. É assim suportada como positiva a relação entre ambas.

Morgan et al. (2006) referem que o crescimento é uma importante meta para as empresas exportadoras, tendo em conta os seus esforços para ampliação de vendas e quotas de receitas provenientes do mercadoalvo exportador. Serve de indicador de medida de efetividade dos resultados. Relativamente ao Grupo EFACEC, podemos constatar a existência de um significativo crescimento das vendas entre os anos de 2008 e 2010, ou seja, passaram de 642M€ para $1.015 \mathrm{M} €)$, verificando-se um crescimento do peso das vendas em mercados exteriores de, respectivamente, $51 \%$ para $66 \%$ (EFACEC, 2010). 
Em resultado do estudo sobre desempenho e internacionalização, numa perspetiva de aprendizagem, Ruigrok e Wagner (2003, p. 77) concluíram que uma vez ultrapassado o período de adaptação, as multinacionais estão aptas a colher rapidamente os benefícios dos investimentos nos processos de internacionalização.

Dois tipos de fatores internos foram identificados por Zou e Stan (1998) num estudo transversal sobre a literatura relativa à internacionalização, no período entre 1987 e 1997, que são determinantes do desempenho das exportações: os controláveis e os incontroláveis. Nos primeiros, encontram-se as estratégias de marketing internacional e o gesto de atitudes e percepções. Nos segundos, identificam-se as caraterísticas da empresa, competências da empresa e caraterísticas de gestão. Entre os fatores internos incontroláveis, encontra-se a compreensão da perceção dos gestores que, segundo Axinn (1988, citado por Sacramento, Almeida e Silva, 2002), é relevante para os estudos sobre a exportação, uma vez que indica o grau provável de envolvimento da empresa no processo de internacionalização, denotando uma visão positiva ou negativa.

P5: As caraterísticas do mercado influenciam positivamente o desempenho das exportações?

Em abono do conjunto de evidências recolhidas e os contributos da literatura nesta matéria, consideramos esta questão como suportada, havendo uma relação positiva entre a obtenção de vantagem competitiva e as caraterísticas do mercado.

Cada país tem as suas peculiaridades que devem ser compreendidas. Fatores como, idioma, religião, nível educacional, clima, cultura, economia, infraestruturas, recursos económicos e ambientais, distribuição demográfica e legislação, entre outros, devem ser tidos em consideração nas de definiçõos estratégicas (Schneider, 2002).

O meio ambiente nos seus distintos contextos, económico, sócio cultural, político-legal e tecnológico, determina as caraterísticas do mercado (Freire, 2008). As caraterísticas desses diferentes contextos são determinantes na obtenção de vantagem competitiva. Kotler (1996) refere que a adoção de estratégias de marketing eficazes, para além de serem essenciais para satisfazer os consumidores, são preponderantes na identificação das suas necessidades. Estas determinam os melhores mercados que a empresa deve atender, permitem planear produtos, serviços e adequar preço, fazer promoção e distribuição com o intuito de satisfazer os seus consumidores mais eficientemente que os seus concorrentes. A fim de adoptar estratégias de marketing internacional consistentes com a realidade do mercado, é necessário que as empresas apresentem uma estrutura organizacional eficiente, capaz de fornecer vantagens diferenciais e possibilitar que gestores orientados internacionalmente tenham condições de utilizar seus atributos na prossecução dos objetivos relativos ao desenvolvimento das exportações. Além disso, é essencial que as empresas tenham elevado grau de envolvimento nas atividades de exportação, pois, dessa forma, tornam-se mais comprometidas e apresentam melhores condições para adoptar estratégias de marketing internacional, capazes de sustentar um posicionamento competitivo no mercado (Bueno e Aguiar, 2004). Estes autores referem ainda que tendo em conta estes aspetos, entende-se que o grau de envolvimento das empresas nas atividades internacionais é um fator decisivo na definição de tais estratégias e, consequentemente, no desempenho das exportações.

\section{DISCUSSÃO E CONCLUSÃO}

Não existe uma "receita única" capaz de definir a melhor estratégia para uma empresa no mundo globalizado dos negócios. Para obtenção de um desempenho excecional, as empresas precisam vencer a concorrência, com uma gestão singular, desenvolvendo competências que as distingam dos outros competidores. Somente assim poderão conseguir obter vantagem competitiva, construindo-as.

O conjunto das vantagens e desvantagens detidas pelas empresas definiria a sua posição concorrencial face aos seus competidores. A sustentabilidade da posição concorrencial implica, em primeira mão, fazer uma contínua avaliação das forças do mercado, uma vez que o contexto concorrencial evolui consoante a pressão destas e da ação dos competidores, levando a novos posicionamentos.

Para que o processo da internacionalização possa ser bem sucedido importa, antes de mais, planeálo adequadamente, iniciando-se pela identificação do modo de entrada no mercado externo. Através da análise dos custos, benefícios e riscos associados a este processo é possível eleger o caminho mais adequado à empresa. Tal implica definir recursos, capacidades e competências internos da empresa, compreender os procedimentos e meandros do processo e conhecer os mercados onde se vai operar, nomeadamente os players, a legislação, as necessidades, as diferenças culturais, a língua, os incentivos e as barreiras. Prosseguindo, deve avaliar-se qual o caminho que melhor se adequada à empresa, a adatação ou a estandardização.

Verificamos que a internacionalização potencia positivamente a obtenção de vantagem competitiva condicionando a seleção da estratégia de internacionalização mais apropriada à matriz produto/mercado, levando as empresas a ter de redefinir os seus recursos e capacidades para que melhor possam ajustar a sua oferta aos mercados de destino, fato que permitirá não somente satisfazer as 
necessidades os seus clientes mais também obter vantagem competitiva sobre os seus concorrentes.

A internacionalização influencia e é influenciada moderadamente pelas caraterísticas da indústria, isto é, a definição de estratégias de internacionalização está condicionada pela idade do mercado e pela respetiva intensidade concorrencial, devendo as empresas equacionarem o estabelecimento de parcerias e/ou alianças estratégicas.

Verificamos ainda que as caraterísticas da indústria influenciam moderadamente a obtenção de vantagem competitiva, pois se em mercados com altas barreiras à entrada como economias de escala o sucesso na competição é mais facilmente atingível, o mesmo não se poderá dizer quanto aos mercados que privilegiam a diferenciação, face à maior intensidade das suas forças competitivas.

Quanto ao fato da obtenção de vantagem competitiva influenciar positivamente o desempenho das exportações concluímos que, após o período de adaptação necessário e habitiual aos mercados, as empresas conseguem aumentar o seu volume de exportações, expressos no crescimento das suas vendas.

Finalmente, as caraterísticas do mercado influenciam positivamente o desempenho das exportações, na medida em que as empresas que melhor (e mais rapidamente) ajustam a sua cultura organizacional à cultura dos países dos seus mercados de destino apresentam uma maior adoção dos seus produtos por parte dos clientes, com impacto positivo no crescimento das vendas.

As conclusões anteriormente apresentadas devem ser analisadas no contexto das suas limitações específicas. Apesar do Grupo EFACEC ser a mais expressiva empresa portuguesa da indústria metalomecânica, tratando-se de um estudo de caso único, a generalização, ou transferibilidade, teórica dos resultados dever-se-á realizar com prudência, preferencialmente a grandes empresas.

Cabe ainda realçar algumas limitações do presente estudo, podendo estas servir de base para temas futuros de investigação. Destacamos a dificuldade em recolher dados relativos à concorrência da empresa estudada nos vários mercados de referência, a reorientação das proposições de investigação tendo em consideração o conjunto de evidências reunidas e a análise efetuada neste estudo (podendo equacionar-se a junção de novos insights para dar origem a novos estudos), a utilização de outro tipo de metodologias para se poder retirar novas conclusões (tal poderia concretizar-se pela combinação de metodologias qualitativas vs. quantitativas, reforçando-se assim a sua complementaridade e sinergia) e o estudo do impacto das redes e das alianças estratégicas nas estratégias de internacionalização.

\section{REFERÊNCIAS}

Ambler, T.; Styles, C.; Xiucun, W. (1999) The effect of channel relationships and guanxi on the performance of inter-province export ventures in the People's Republic of China, International Journal of Research in Marketing, 16, 75-87.

Anastassopoulos, J.-P.; Détrie, J.-P.; Santi, M. et al. (2000) Strategor: Estratégia, Estrutura, Decisão, Identidade, Política Global de Empresa, $3^{\text {a }}$ edição, Lisboa: Publicações Dom Quixote.

Amit, R.; Schoemaker, P. (1993) Strategic assets and organizational rent, Strategic Management Journal, 14, 33-46.

António, N. S. (2006) Estratégia organizacional - do posicionamento ao movimento, 2. ${ }^{\mathrm{a}}$ edição. Lisboa: Edições Sílabo.

Arbix, G.; Salerno, M. S.; Negri, J. A. (2004) Inovação via internacionalização, faz bem para as exportações brasileiras, Atas do XVI Fórum Nacional Economia do Conhecimento, Crescimento Sustentado e Inclusão Social, Maio, Rio de Janeiro, Brasil.

Arruda, C. M.; Prata, B. A.; Moreira, C. A. L. (2007) O mito da globalização no cenário industrial mundial e seus impactos na economia do Brasil. Atas do XXVIII Encontro nacional de engenharia de Produção, Outubro, Foz do Iguaçú, PR. Brasil.

Axelsson, B.; Johanson, J. (1992) Foreign market entry - The Textbook vs. The network view, in Axelsson, B. \& Easton G. (eds) Industrial Networks. A New View of Reality, Routledge, London, 218-234.

Barney, J. (1991) Firm Resources and sustained competitive advantage, Journal of Management, 17(1), 99-120.

Barney, J. (2001) Is the resource-based "view" a useful perspective for strategic management research? Yes, Academy of Management Review, 26(1), 4158.

Barney, J.; Wright, M.; Ketchen Jr. D. J. (2001) The resource-based view of the firm: ten years after 1991, Journal of Management, 27, 625-641.

Beard, J.; Sumner, M. (2004) Seeking strategic advantage in the post-net era: viewing ERP systems from the resources-based perspective, Journal of Strategic Information Systems, 13, 129-150. 
Bradley, F. (1995) International marketing strategy, 2nd ed, London: Prentice-Hall International.

Britto, R. P.; Mizumoto, F. M.; Borini, F. M. (2006) Recursos e capacidades estratégicas para internacionalização. Atas do IX SEMEAD, Faculdade de Economia, Administração e Contabilidade da Universidade de São Paulo, Agosto, Brasil.

Bueno, Y. M.; Aguiar, D. R. D. (2004) Determinantes do grau de envolvimento na actividade exportadora e suas implicações nas exportações brasileiras de carne de frango, Gestão \& Produção, 11(2), 211220.

Cavusgil, S. T.; Zou, S. (1994) Marketing strategyperformance relationship: an investigation of the empirical link in export market ventures, Journal of Marketing, 58, 1-21.

Covielo, N.; Munro, H. (1997) Network relationship and internationalisation process of small software firms, International Business Review, 6(2), 1-26.

Dalmoro, M.; Wittmann, M. (2011) Processos de internacionalização em rede: cooperando para conquistar o mercado, Revista de Administrção e Contabilidade da Unisinos, 8(3), 231-242.

Davis, D. F.; Mentzer, J. T. (2008) Relational resources in interorganizational exchange: the effects of trade equity and brand equity, Journal of Retailing, 84(4), 435-448.

Deegan, C.; Gordon, B. (1996) A study of the environmental disclosure practices of Australian corporations. Accounting and Business Research, 26(3), 187-99.

Denzin, N. K. (1978) Sociological Methods: A Source Book. 2nd ed. New York: McGraw-Hill.

Dias, M. C. (2007) A internacionalização e os factores de competitividade: o Caso Adira. Dissertação de mestrado, Faculdade de Economia da Universidade do Porto, Porto.

Dominguinhos, P. M. (2001) A internacionalização das empresas portuguesas: realidades e desafios, Atas do 9. ${ }^{\circ}$ Encontro de economia Industrial, Janeiro, Leiria, Portugal.

EFACEC (2009) Relatório e contas. Demonstrações financeiras consolidadas e individuais de 2009, EFACEC, Portugal.
EFACEC (2010) 2009 Report: Broad of Director's Report and Consolidated and individual finance statements, EFACEC, Portugal.

EFACEC (2011) Relatório e contas. Demonstrações financeiras consolidadas e individuais de 2010, EFACEC, Portugal.

Ferreira, J. J.; Azevedo, S. G.; Fernandéz, R. (2010) Contribution of Resourse-Based View and Entrepreneurial Orientation on Small Firm Growth, Cuadernos de Gestión, 11(1), 95-116.

Forte, S. H. C.; Moreira, M. Z. (2007) Competitividade internacional baseada em recursos: Estudo da relação entre os recursos e as estratégias de internacionalização nas maiores empresas exportadoras do sector calçadista brasileiro, Revista de Ciência e Administração, 9(17), 1-25.

Freire, A. (2008). Estratégia - sucesso em Portugal. Lisboa: Editorial Verbo.

Gaspar, M. A.; Oliva, F. L.; Zebinden, W. S. A. (2007) A internacionalização da Construtora Norberto Odbrecht. Atas do X Encontro SEMAD, São Paulo.

Grant, R. M. (1991) The resourse-based theory of competitive advantge: implications for strategy formulation, California Managment Review, Spring, 114-135.

Gulati, R.; Nohria, N.; Zaheer, A. (2000) Strategic Networks, Strategic Management Journal, 21, 203215 .

Hackston, D.; Milne, M. (1996) Some determinants of social and environmental disclosures in New Zealand companies. Accounting, Auditing and Accountability Journal, 9(1), 77-108.

Håkansson, H.; Johanson, J. (1984) A model of industrial networks, Working paper, University of Upsala.

Harris, S.; Wheeler, C. (2005) Entrepreuner's relationships for interanationalization: functios, origins and strategies, International Business Review, 14, 187-207.

Hitt, M. A.; Ireland, R. D.; Hoskisson, R. E. (2008) Administração Estratégica (Eliane Kanner, Maria Emília Guttila, All Tasks, Trad.), 2. ${ }^{a}$ edição, São Paulo: Thomson.

Janesick, V. J. (1994) The dance of qualitative research design: metaphor, methodolatry, and meaning. In N., K., Denzin, \& Y., S. Lincoln, (Ed.). Handbook 
of Qualitative Research. Thousands Oaks, CA: Sage Publications.

Johanson, J.; Mattsson, J. (1988) Internationalization in industrial system: a network approach, in N. Hood \& J. E. Valhne (Ed.). Strategies in global competition, New York: Croom Helm.

Johanson, J.; Wiendersheim-Paul, F. (1975) The internationalization of the firm - four Swedish cases, Journal of Management Studies, 12(3), 305323.

Johanson, J.; Vahlne, E. (1990) The Mechanism of Internationalization. International Marketing Review, 7(4), 11-24.

Johanson, J.; Vahlne, J.-E. (1990). The mechanism of internationalization. International Marketing Review, 7(4), 11-24.

Johanson, J.; Vahlne, E. (2009) The Uppsala internationalization process model revisited: From liability of foreignness to liability of outsider ship, Journal of international Business Studies, 40, 14111431.

Kotler, P. (1996) Administração de marketing: análise, planejamento, implementação e contrôle, São Paulo: Atlas.

Levit, T. (1998) A globalização dos mercados.(Ed.). In C. K. Prahalad et al. (1998). Estratégia: a busca da vantagem competitiva, (Ed.). Harvard Business Review. Rio de Janeiro: Campus Editora.

Lee, J.-S.; Hsien, C.-J. (2010) A research in relating entrepreneurship, marketing capability, innovative capability and sustained competitive advantage, Journal of Business \& Economics Research, 8(9), 109-120.

Lorga, S. (2002) A internacionalização e os mecanismos de cooperação em rede na Vitrocristal, Working Paper 02/001, Faculdade de Economia da Universidade Católica Portuguesa, Porto.

Mais, I.; Carvalho, L. C.; Amal, M.; Hoffmann, M. G. (2009) Importância das redes nos processos de inovação e internacionalização de empresas de base tecnológica, 5éme Colloque de l'IFABAE, Mai, Grenoble.

Maçães, M.; Dias, J. (2001) Internacionalização: Estudo empírico no sector do vinho do porto, Revista Portuguesa de Gestão, Jul/Ago/Set, 72 -90.
Makadok, R. (2001) Toward a synthesis of the resource-based and dynamic-capability views of rent creation, Strategic Management Journal, 22(5), $387-401$.

Makadok, R. (2001) Toward a synthesis of the resourse-based and dynamic-capability views of rent creation, Strategic Management Journal, 22, 387-401.

Miller, D.; Shamsie, J. (1996) The Resources-Based View of The firm in two environments: the Hollywood film studios from 1936 to 1965 , Academy of Management Journal, 39 (3), 519-543.

Mesquita, A. C.; Ribeiro, T. B. (2008) Globalização e internacionalização empresarial: o caso da Efacec, Atas do 1. ${ }^{\circ}$ Encontro de Educação Corporativa Brasil/Europa, Universidade Fernando Pessoa, Porto, Portugal.

Moreno, C. (2005) Os factores da inovação e a internacionalização. Recuperado em 17 fevereiro de 2011 de http://www.janusonline.pt/2005/2005_2_2.html.

Morgan, N. A.; Kaleka, A; Katsikeas, C. S. (2004) Antecedents of export venture performance: a theoretical model and empirical assessment. Journal of Marketing, 68, 90-108.

Morgan, R. M.; Hunt, S. (1994) The Commitment trust theory of relationship marketing. Journal of Marketing, 58, 20-38.

Morgan, N. A.; Shaoming, Z.; Vorhies, D. W.; Katsikeas, C. S. (2003) Experiential and informational knowledge, architectural marketing capabilities, and the adaptive performance of export venture: a cross-nationalstudy, Decision Sciences, 34(2), 287-321.

Okpara, J. O. (2009) Entrepreneurial orientation and export performance: evidence from an emerging economy, International Review of Business Research Papers, 5(6), 195-211.

Oliveira, L. (2004) A Estratégica organizacional na competitividade: um estudo teórico. Universidade Federal de Lavras, Departamento de Administração e Economia. Lavras/MG: Read, Ed. 40, 10 (4). Recuperado em 05 de outubro de 2010, de http://read.adm.ufrgs.br/edicoes/pdf/artigo_175.pdf

Oviatt, B. M.; McDougall, P. P. (1994) Toward a theory of international new ventures, Journal of International Business Studies, 25, 46-64. 
O Papel da Vantagem Competitiva na Relação entre Internacionalização e Desempenho das Exportações: Estudo de Caso da EFACEC

Oviatt, B.; McDougall, P. (1995) Global strat-ups: entrepreneurs on a worldwide stage, Academy of Management Executive, 9(2), 30-43.

Patton, M. (1990) Qualitative evaluation and research methods, Newbury Park, CA: Sage Publications.

Pedersen, T. (1999) The internationlization process of Danish firms - gradual learning or discrete rational choices? Recuperado em 17 de fevereiro de 2011, de http://openarchive.cbs.dk/bitstream/handle/10398/6 572/wp4.pdf?sequence $=1$.

Pedersen, T.; Shaver, J. M. (2000) Internationalization revisited: the big step hypotheses, Copenhaghen Business School, March. Recuperado em 17 de fevereiro de 2011, de http://openarchive.cbs.dk/bitstream/handle/10398/6 607/wp5-2000tp.pdf?sequence $=1$

Peng, M. W. (2008). Estratégia global, (Vértice Translate, Trad.), São Paulo: Thomson.

Porter, M. E. (1981) The contribution of industrial organization to strategy management, The Academy of Management Review, 6(4), 609-620.

Porter, M. E. (1999) Competição: estratégias competitivas essenciais, (Afonso Celso da Cunha Serra, Trad.), Rio de Janeiro: Campus Editora.

Ramos, A. F. (2004) O Movimento de internacionalização empresarial na indústria do vestuário - o caso Português. Recuperado em 10 de outubro de 2010, de http://www4.crb.ucp.pt/Biblioteca/GestaoDesenv/G D12/gestaodesenvolvimento12 47.pdf.

Rezende, S. F. L. (2002) Gradualismo e descontinuidade em processos de internacionalização, Revista de Administração da Universidade de São Paulo, 37(1), 39-50.

Rodríguez, G.; Gil, F. J.; García, J. E. (1996) Metodología de la Investigación Cualitativa, Ediciones Aljibe, Málaga.

Rua, O. M. (2012) The impacts of leadership in the quality of municipal public services: case study of a portuguese municipal council, Cuadernos de Gestión, 12(2), 131-147.

Rua, O. M.; Melo, L. R. (2013) Construção de vantagens competitivas nas estratégias de internacionalização: um estudo de caso, Proceedings of the XXIII Spanish-Portuguese
Scientific Management Conference, Universidad de Málaga, Málaga, Spain.

Ruigrok, W.; Wagner, H. (2003) Internationalization and performance: an organizational learning perspective, Management International Review, 43, pp. 63-83.

Runyan, R.; Huddleston, P.; Swinney, J. (2006) Entrepreneurial orientation and social capital as small firm strategies: a study of gender differences from a Resource-Based View, Entrepreneurship Management, 2, 455-477.

Sacramento, I.; Almeida, V. M. C.; Silva, M. S. M. (2002) The internationalization process of services firms: a two-case study in Brazil, Latin American Business Review, 2(2), 43-64.

Schneider, A. C. (2002) O processo de internacionalização de uma empresa do sector moveleiro: um estudo de caso, Dissertação de Mestrado, Universidade Federal Rio Grande do Sul. Porto Alegre, RS, Brasil.

Silva, E. B. Filho. (2006) A teoria da firma e a abordagem dos custos de transacção: elementos para uma crítica institucionalista, Pesquisa \& Debate, 17, 2(30), 259-277.

Silva, M. J. (2007) O papel da inovação e do conhecimento na construção da competitividade regional, Atas da 4. ${ }^{\text {a }}$ Conferência de Engenharia 'Engenharia' 2007 - Inovação e Desenvolvimento. Covilhã, 433-438.

Simões, V. C. (1997) Estratégias de internacionalização das empresa portuguesas. In ICEP - Investimentos, comércio e turismo de Portugal. (Ed.). Comércio e investimento internacional. Lisboa: ICEP.

Stokes, D. (2000) Entrepreneurial Marketing: A Conceptualisation from Qualitative Research, Qualitative Market Research, 3(1), 47-54.

Sousa, M. J.; Baptista, C. S. (2011) Como fazer investigação, dissertações, teses e relatórios. Segundo Bolonha, Lisboa: Pactor.

Sousa, C. M. P.; Martínez-López, F. J.; Coelho, F. (2008) The determinants of export performance: a review of the research in the literatures between 1998 and 2005, International Journal of Management Reviews, 10(4), 343-374. 
O Papel da Vantagem Competitiva na Relação entre Internacionalização e Desempenho das Exportações: Estudo de Caso da EFACEC

Teece, D. J.; Pisano, G.; Shuen, A. (1997) Dynamic capabilities and strategic management, Strategic Management Journal, 18(7), 509-533.

Teixeira, S.; Diz, H. (2005) Estratégias de internacionalização, Lisboa: Publisher Team.

Thiergarten, M.; Alves, C. A. (2008) A visão baseada em recursos (RBV) como estratégia empresarial: um estudo das principais abordagens a partir de um quadro de referenciais teóricos, Revista Universo Administração, 2(2), 61-74.

Unerman, J. (2000) Methodological issues. Reflections on quantification in corporate social reporting content analysis. Accounting, Auditing and Accountability Journal, 13(5), 667-680.

Vasconcelos, F. C.; Cyrino, A. B. (2000) Vantagem competitiva: os modelos teóricos actuais e a convergência entre estratégia e teoria organizacional, Revista de Administração de Empresas, 40 (4), pp. 20-37.

Vila, N.; Kuster, I. (2007) The importance of innovation in international textile firms, European Journal of Marketing, 41(1/2), 17-36.

Yin, R. (1994) Case Study Research: Design and Methods. Applied Social Research Methods Series, $5,2^{\text {nd }}$ ed. Thousands Oaks, CA: Sage Publications.

Yin, R. (1998) The Abridged Version of Case Study Research, in L. Bickman e D. J. Rog (eds.):
Handbook of Applied Social Research Methods, Sage Publications, Thousand Oaks, 229-259.

Yin, R. (2005) Estudo de Caso: Planejamento e Métodos, 3. ${ }^{\mathrm{a}}$ ed, Porto Alegre: Bookman.

Zeghal, D.; Ahmed, S. A. (1990) Comparison of social responsibility information disclosure media used by Canadian firms, Accounting, Auditing and Accountability Journal, 3 (1), 39-53.

Wernerfelt, B. (1984) A resource-based view of the firm”, Strategic Management Journal, 5, 171-180.

Vol. 5, pp. 171-180. Zohari, T. (2008) The Uppsala internationalization model and its limitation in the new era, Stockholm University School of Business, October. Recuperado em 17 de fevereiro de 2011, de

http://www.digitpro.co.uk/paper/The\%20Uppsala\% 20Internationalization\%20Model_web.pdf

Zou, S.; Stan, S. (1998) The determinants of export performance: a review of empirical literature between 1987 and 1997, International Marketing Review, 15, 333-356.

Zou, S.; Taylor, C. R.; Osland, G. E. (1998) The EXPERF scale: A cross-national generalized export performance measure, Journal of International Marketing, 6(3), 37-58. 